\title{
EFEITO DE FERTILIZANTE À BASE DE URINA DE VACA E SUBSTRATOS EM PLANTAS DE PIMENTÃO
}

\author{
EFECTO DE ABONO ORINA DE VACA BASE Y SUSTRATO EN PLANTAS DE \\ CHILE
}

\section{EFFECT OF FERTILIZER TO COW URINE BASE AND SUBSTRATE IN CHILI PLANTS}

\author{
Danila Lima de ARAÚJO ${ }^{1}$ \\ Mário Leno Martins VÉRAS ${ }^{2}$ \\ Lunara de Sousa ALVES ${ }^{3}$ \\ Alexandro de Figueiredo ANDRADE ${ }^{4}$ \\ Raimundo ANDRADE ${ }^{5}$
}

\begin{abstract}
RESUMO: Objetivou-se com este trabalho avaliar o efeito de fertilizante a base de urina de vaca e substratos em plantas de pimentão. A pesquisa foi realizada em condições de campo na Escola Estadual de Ensino Fundamental e Médio Nossa Senhora da Conceição no município de Belém de Brejo do Cruz - PB. O delineamento experimental adotado foi o de blocos casualizados (DBC) com quatro repetições, no arranjo fatorial 5 x 2, totalizando 40 plantas. Estudou-se 5 doses de urina de vaca: $\left(\mathrm{D}_{1}=0 \mathrm{~mL}, \mathrm{D}_{2}=25 \mathrm{~mL}, \mathrm{D}_{3}=50 \mathrm{~mL}, \mathrm{D}_{4}=75 \mathrm{~mL}\right.$ e $\mathrm{D}_{5}=$ $100 \mathrm{~mL}$ ) e a combinação de substratos: $\mathrm{S}_{1}=$ pó de madeira + esterco bovino + areia lavada (proporção 1:1:1) e $S_{2}=$ esterco bovino + areia lavada (proporção 2:1). Verificou-se que as doses de urina de vaca influenciaram estatisticamente a nível de $(\mathrm{p}<0,01)$ todas as variáveis analisadas, observou-se também que todas as variáveis sofreram efeitos significativos a nível de $(\mathrm{p}<0,01)$ quando submetido aos substratos. A dosagem de $100 \mathrm{~mL}$ de solução a base de urina de vaca proporcionou bons resultados no pimentão. Substratos com esterco bovino + areia lavada na proporção $2: 1 \mathrm{v} / \mathrm{v}$ são ótimos para a cultura do pimentão.
\end{abstract}

Palavras-chave: Capsicum annuum L.; urina de vaca; resíduos agrícolas.

RESUMEN: El objetivo de este estudio fue evaluar el efecto de los sustratos a base de orina abono de vaca y plantas de pimentón. La investigación se realizó en condiciones de campo en la Escuela Primaria Estatal y Secundaria Nuestra Señora de la Concepción en la ciudad de

\footnotetext{
${ }^{1}$ Mestre em Engenharia Agrícola, Universidade Federal de Campina Grande - UFCG - Campina Grande Paraíba - Brasil. danilalimaraujo@ hotmail.com

${ }^{2}$ Mestrando em agronomia, Universidade Federal da Paraíba - UFPB/Campus II - Areia - Paraíba - Brasil. mario.deus1992@bol.com.br

${ }^{3}$ Graduada em Ciências Agrárias, Universidade Estadual da Paraíba - UEPB/Campus IV - CEP 58884-000 -

Catolé do Rocha - Paraíba - Brasil. lunara_alvesuepb@hotmail.com

${ }^{4}$ Graduado em Ciências Agrárias, Universidade Estadual da Paraíba - UEPB/Campus IV - CEP 58884-000 Catolé do Rocha - Paraíba - Brasil. afigueiredoandrade@bol.com.br

${ }^{5}$ Prof. Doutor do Departamento de Agrárias e Exatas, Universidade Estadual da Paraíba - UEPB/Campus IV CEP 58884-000 - Catolé do Rocha - Paraíba - Brasil. raimundoarndrade@uepb.edu.br
} 
Belem do Brejo do Cruz - PB. El diseño experimental fue de bloques completos al azar (RBD) con cuatro repeticiones, en un arreglo factorial $5 \times 2$, por un total de 40 plantas. $5 \mathrm{Se}$ estudió la orina dosis vaca: $\left(\mathrm{D}_{1}=0 \mathrm{~mL}, \mathrm{D}_{2}=25 \mathrm{~mL}, \mathrm{D}_{3}=50 \mathrm{~mL}, \mathrm{D}_{4}=75 \mathrm{~mL}\right.$ e $\left.\mathrm{D}_{5}=100 \mathrm{~mL}\right)$ y los sustratos combinados: $S_{1}=$ estiércol de polvo de madera ++ arena lavada $(1: 1: 1)$ e $S_{2}=$ estiércol + arena lavada (2: 1 ratio). Se ha encontrado que las dosis de orina de vaca estadísticamente influyen en el nivel $(\mathrm{p}<0,01)$ todas las variables, también se observó que todas las variables han sufrido un efecto significativo $(\mathrm{p}<0,01)$ en las pruebas los sustratos. Una dosis de $100 \mathrm{ml}$ de solución de orina de vaca proporciona buenos resultados con base en chile. Sustratos con estiércol de ganado + arena lavada en una relación 2: $1 \mathrm{v} / \mathrm{v}$ son grandes para los cultivos de pimiento.

Palabras-clave: Capsicum annuиm L.; orina de vaca; residuos agrícolas.

\begin{abstract}
The objective of this study was to evaluate the effect of fertilizer cow urinebased substrates and bell pepper plants. The research was conducted under field conditions at the State Elementary School and Middle School Our Lady of the Conception in the city of Belem do Brejo do Cruz - PB. The experimental design was a randomized complete block design (RBD) with four replications, in a factorial arrangement $5 \times 2$, totaling 40 plants. 5 was studied doses cow urine: $\left(\mathrm{D}_{1}=0 \mathrm{~mL}, \mathrm{D}_{2}=25 \mathrm{~mL}, \mathrm{D}_{3}=50 \mathrm{~mL}, \mathrm{D}_{4}=75 \mathrm{~mL}\right.$ e $\left.\mathrm{D}_{5}=100 \mathrm{~mL}\right)$ and the combined substrates: wood powder $\mathrm{S}_{1}=$ wood powder manure ++ washed sand (1: 1 : 1) and $S_{2}=$ manure + washed sand (2: 1 ratio). It has been found that the cow urine doses statistically influence the level $(\mathrm{p}<0.01)$ all variables, it was also observed that all variables have suffered from significant effect $(\mathrm{p}<0.01)$ when tested the substrates. A dosage of $100 \mathrm{ml}$ of cow urine solution provided good results based on chili. Substrates with cattle manure + sand washed in a $2: 1 \mathrm{v} / \mathrm{v}$ are great for bell pepper crop.
\end{abstract}

Keywords: Capsicum annuum L.; cow urine; residuos agrícolas.

\title{
INTRODUÇÃO
}

O pimentão (Capsicum annuum L.) pertence à família das Solanáceas tipicamente de origem americana, ocorrendo em formas silvestres desde o Sul dos Estados Unidos da América até o Norte do Chile (LEME, 2012).

Essa hortaliça é consumida nacionalmente, sendo cultivado tanto em ambiente protegido como em campo aberto irrigado por sulco, onde sua produtividade varia de 25 toneladas $\mathrm{ha}^{-1}$ e 50 toneladas $\mathrm{ha}^{-1}$. Atual no Brasil a área de cultivo de pimentão é aproximadamente 13 mil hectares, com produção próxima a 290 mil toneladas de frutos. Os principais estados produtores são: São Paulo, Minas Gerais, Bahia e Rio de Janeiro (MAROUELLI e SILVA, 2012). Representa enorme relevância econômica no mundo (LEME, 2012). 
Essa cultura está entre as dez hortaliças mais relevantes economicamente, devido ser uma cultura de retorno rápido aos investimentos, pelo curto período para o início da produção, por isto é largamente explorada por pequenos e médios horticultores (ALBUQUERQUE et al., 2011).

Leme (2012) trabalhando com pimentão orgânico observou que a produção orgânica desta hortaliça apresentou melhor qualidade pós-colheita por apresentar frutos mais verdes, mais firmes, maior $\mathrm{pH}$, menor teor de sólidos solúveis, maior teor de compostos fenólicos totais e maior atividade antioxidante ao longo do armazenamento.

Para o cultivo orgânico de hortaliças deve-se levar em consideração um fator que um sistema de produção formado apenas por olerícolas é altamente desgastante quanto à fertilidade do solo. Os restos culturais das hortaliças são de natureza tenra, raramente lenhosa, contribuindo muito pouco para manutenção da fertilidade das áreas onde são produzidas (perde apenas para a produção de forrageiras, silagem e feno). Na maioria das vezes, grandes quantidades de massa vegetal são retiradas da área, necessitando de reposições constantes de biomassa e nutrientes minerais para se manter (RESENDE e VIDAL, 2011).

Os fertilizante orgânicos atuam no solo enriquecendo gradualmente o solo com macro e micronutrientes essenciais às plantas e o aumento gradativo do teor de matéria orgânica do solo (TRANI et al., 2013). Sob os aspectos biológicos do solo, os fertilizantes aumentam a biodiversidade de microorganismos úteis que agem na solubilização de fertilizantes diversos de maneira a liberar nutrientes para as plantas, além disso, aumentam a quantidade de microorganismos que auxiliam no controle de nematóides, que são pragas que atacam as raízes das plantas.

Dentre os fertilizantes orgânicos, a urina de vaca é um produto orgânico, considerado subproduto da exploração leiteira, vem sendo utilizada por agricultores a partir da última década em culturas olerícolas e frutíferas (GADELHA et al., 2002, 2003; PESAGRO-RIO, 2001). Este fertilizante orgânico está disponível na maioria das propriedades rurais. Apresenta muitas vantagens como o baixo custo de aquisição permitindo a integração das atividades da pecuária e da horticultura (OLIVEIRA et al., 2009, 2010). Resultados positivos em crescimento e produção foram constatados com pulverizações de solução de urina de vaca em tomate, pimentão, pepino, feijão-vagem, couve, alface e beterraba de mesa (PESAGRO-RIO, 2002; GADELHA et al., 2002, 2003; OLIVEIRA et al., 2009, 2010, 2012).

O uso de substratos no cultivo de hortaliças vem crescendo consideravelmente entre os produtores de hortaliças, sendo utilizado principalmente na produção de hortaliças tipo fruto, dentre estas algumas espécies da família das cucurbitáceas, principalmente meloeiro (DIAS et 
al., 2010) e pepino (SILVA et al., 2011). Neste tipo de cultivo, na maioria das vezes utiliza-se substrato inerte, de tal forma que se torna necessário o fornecimento de nutrientes via fertirrigação para atender às necessidades nutricionais das plantas (DIAS et al., 2010; CHARLO et al., 2011).

Neste sentido, o objetivo do trabalho foi avaliar o efeito de fertilizante a base de urina de vaca e substratos em plantas de pimentão.

\section{MATERIAL E MÉTODOS}

A pesquisa foi realizada em condições de campo na Escola Estadual de Ensino Fundamental e Médio Nossa Senhora da Conceição no município de Belém de Brejo do Cruz - PB. O referido município está situado na região semiárida do Nordeste brasileiro, no Noroeste do Estado da Paraíba, cujas coordenadas geográficas são: 60 28'12” de latitude Sul, 370 20'32" de longitude oeste de Greenwich tendo uma altitude de $176 \mathrm{~m}$. O clima do município, de acordo com a classificação de Köppen, é do tipo BSWh', ou seja, seco, muito quente do tipo estepe, com estação chuvosa no verão e com temperatura do mês mais frio superior a $18^{\circ} \mathrm{C}$.

O delineamento experimental adotado foi o de blocos ao acaso, com 40 tratamentos, no esquema fatorial 5 x 2, com 4 repetições. Foram estudados os efeitos de 5 dosagens de urina de vaca: $\left(D_{1}=0 \mathrm{~mL}, D_{2}=25 \mathrm{~mL}, D_{3}=50 \mathrm{~mL}, D_{4}=75 \mathrm{~mL}\right.$ e $\left.D_{5}=100 \mathrm{~mL}\right)$, aplicadas via solo e da combinação de substratos: $S_{1}=$ pó de madeira + esterco bovino + areia lavada (proporção 1:1:1) e $S_{2}=$ esterco bovino + areia lavada (proporção 2:1). O plantio foi feito em baldes de plástico com capacidade de $10 \mathrm{~L}$.

A água utilizada na irrigação apresentou condutividade elétrica de $0,8 \mathrm{dS} / \mathrm{m}$. A análise da água foi realizada pelo Laboratório de Irrigação e Salinidade (LIS) do Centro de Tecnologia e Recursos Naturais da Universidade Federal de Campina Grande - UFCG. E apresentou as seguintes características químicas: $\mathrm{pH}=8,53 ; \mathrm{Ca}=2,40\left(\mathrm{cmol}_{\mathrm{d}} / \mathrm{dm}^{3}\right) . \mathrm{Mg}=1,36$ $\left(\mathrm{cmol}_{\mathrm{C}} / \mathrm{dm}^{3}\right) ; \mathrm{Na}=4,00\left(\mathrm{cmol}_{\mathrm{c}} / \mathrm{dm}^{3}\right) ; \mathrm{K}=0,02\left(\mathrm{cmol}_{\mathrm{C}} / \mathrm{dm}^{3}\right) ;$ Cloreto = 3,60 $\left(\mathrm{cmol}_{\mathrm{C}} / \mathrm{dm}^{3}\right) ;$ Carbonato $=0,47\left(\mathrm{cmol}_{\mathrm{c}} / \mathrm{dm}^{3}\right) ;$ Bicarbonato $=3,55\left(\mathrm{cmol}_{\mathrm{C}} / \mathrm{dm}^{3}\right) ; \operatorname{RAS}=2,88\left(\mathrm{mmol}_{\mathrm{c}} \mathrm{L}^{-1}\right)^{1 / 2}$.

A urina de vaca utilizada no experimento foi coletada de vacas em lactação, de rebanho leiteiro da Escola Agrotécnica do Cajueiro - EAC, município de Catolé do Rocha - PB, pertencente à Universidade Estadual da Paraíba. Para a obtenção da solução nutritiva do fertilizante urina de vaca foi diluído numa concentração de $1 \%$ para ser aplicado via solo. 
Os tratamentos com urina de vaca começaram aos 21 dias após emergência (DAE), daí com intervalo de 8 dias entre as aplicações, sendo feitas 6 aplicações. Foi feita a análise química da urina de vaca e apresentou as seguintes características:

Tabela 1. Atributos químicos da urina de vaca utilizada no experimento do melão. Catolé do Rocha - PB, UEPB, 2014.

\section{ESPECIFICAÇÕES}

\begin{tabular}{|c|c|c|}
\hline 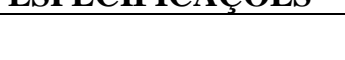 & Valor Obtido $^{3}$ & Valor Transformado ${ }^{3}$ \\
\hline pH & 6,70 & - \\
\hline $\left.\mathbf{C E}\left(\mathrm{dS} \mathrm{m}^{-1}\right)\right)$ & $\mathrm{n} / \mathrm{a}^{*}$ & - \\
\hline NUTRIENTES & - & $\left(\mathrm{g} \mathrm{L}^{-1}\right)$ \\
\hline Nitrogênio (\%) & $0,28 \%$ & 2,80 \\
\hline Fósforo $\left(\mathrm{mg} / \mathrm{dm}^{3}\right)$ & $0,48 \%$ & 4,80 \\
\hline Potássio $\left(\mathrm{cmol}_{\mathrm{c}} \mathrm{L}^{-1}\right)$ & $1,00 \%$ & $\begin{array}{l}4,00 \\
10,00\end{array}$ \\
\hline Cálcio $\left(\mathrm{cmol}_{\mathrm{c}} \mathrm{L}^{-1}\right)$ & $0,03 \%$ & 0,30 \\
\hline Magnésio $\left(\mathrm{cmol}_{\mathrm{c}} \mathrm{L}^{-1}\right)$ & $0,04 \%$ & 0,40 \\
\hline Sódio $\left(\mathrm{cmol}_{\mathrm{c}} \cdot \mathrm{dm}^{-3}\right)$ & $\mathrm{n} / \mathrm{a}$ & - \\
\hline Enxofre $\left(\mathrm{cmol}_{c} \cdot \mathrm{dm}^{-3}\right)$ & $\mathrm{n} / \mathrm{a}$ & - \\
\hline
\end{tabular}

Avaliaram-se: O peso seco da raiz (PSR), peso seco do caule (PSC), peso seco da folha (PSF), número de frutos não comerciais (NFNC), peso de frutos não comerciais (PFNC), peso verde total (PVT) e peso seco total (PST).

Os dados foram analisados e interpretados a partir da análise de variância (Teste F), através da utilização do Programa estatístico SISVAR, pelo confronto de médias do teste TUKEY, a nível de significância de 0,05 (5\%) e 0,01 (1\%) de probabilidade, conforme Ferreira (2007).

\section{RESULTADOS E DISCUSSÃO}

Verificou-se pelos resultados da análise de variância apresentados na Tabela 2 que as doses de urina de vaca influenciaram estatisticamente a nível de significância de $(\mathrm{p}<0,01)$ todas as variáveis analisadas, para todas as variáveis o tipo de regressão adequado a ser utilizado foi quadrático, o mesmo comportamento foi observado para os tratamentos com substratos, onde observou-se que todas as variáveis sofreram efeitos significativos a nível de $(\mathrm{p}<0,01)$. Não houve interação entre os fatores. Os coeficientes de variação oscilaram entre 4,97 a 27,71\% sendo considerados baixos a médios (PIMENTEL GOMES, 2000). 
Tabela 2. Resumo das análises de variância referente ao peso seco da raiz (PSR), peso seco do caule (PSC), peso seco da folha (PSF), número de frutos não comerciais (NFNC), peso de frutos não comerciais (PFNC), peso verde total (PVT) e peso seco total (PST) de plantas de pimentão sob doses de urina de vaca em função de substratos.

\begin{tabular}{|c|c|c|c|c|c|c|c|c|}
\hline \multirow[t]{2}{*}{ Fonte de variação } & GL & \multicolumn{7}{|c|}{ Quadrados Médios } \\
\hline & & PSR & PSC & PSF & NFNC & PFNC & PVT & PST \\
\hline Doses de urina de vaca & 4 & $46 * *$ & $15,1 * *$ & $45,5 * *$ & $2,4 * *$ & $61,9 * *$ & $2111 * *$ & $80,3 * *$ \\
\hline Regressão Linear & 1 & $150,1 * *$ & $4,3 *$ & $25,9 * *$ & $0,45^{\mathrm{ns}}$ & $18^{* *}$ & $1206,6 * *$ & $25,7 *$ \\
\hline Regressão Quadrática & 1 & $24,1 *$ & $21,7 * *$ & $56,8 * *$ & $3,5 * *$ & $101 * *$ & $5531,4 * *$ & $53,2 *$ \\
\hline Substratos & 1 & $67,6 * *$ & $64,7 * *$ & $129,2 * *$ & $5,6 * *$ & $93,6 * *$ & $15665,7 * *$ & $763,8 * *$ \\
\hline Interação (D x S) & 4 & $8,58^{\mathrm{ns}}$ & $20,3^{\mathrm{ns}}$ & $21,2^{\mathrm{ns}}$ & $2,5^{\mathrm{ns}}$ & $49,8^{\mathrm{ns}}$ & $2280,4^{\mathrm{ns}}$ & $84,9^{\mathrm{ns}}$ \\
\hline Resíduo & 30 & 3,49 & 0,70 & 1,13 & 0,12 & 0,49 & 12,7 & 4,51 \\
\hline Desvio de regressão & 2 & 4,9 & 17,2 & 49,7 & 2,8 & 64,3 & 853 & 121,2 \\
\hline $\mathrm{CV}(\%)$ & - & 18,43 & 13,8 & 12,07 & 25,71 & 7,34 & 4,97 & 8,49 \\
\hline
\end{tabular}

Observa-se que as doses de urina de vaca proporcionaram um acréscimo de acordo com o seu aumento para o peso seco da raiz se enquadrando no tipo de regressão quadrática com comportamento convexo, onde os maiores valores foram constatados com a dose de $120 \mathrm{~mL}$ de urina de vaca com o valor máximo de 12,21 g (figura 1A). Esse resultado também foi comprovado por Alencar et al., (2012) quando estudou o efeito da urina de vaca no estado nutricional da alface e mostrou que a aplicação em intervalos de 05 dias obteve maior desenvolvimento da raiz com um rendimento de 13,43 g planta-1 e maior rendimento em massa seca da raiz no tratamento com a solução de urina de vaca em intervalos de 05 dias, com um peso de 1,55 g planta-1. Véras et al (2014) ao trabalharem com mudas de alface sob fertilização orgânica com urina de vaca e volumes de húmus de minhoca também observaram que as doses de urina de vaca influenciaram estatisticamente a nível de $1 \%$ o peso seco da raiz.

Em relação aos substratos, foi observado para o peso seco da raiz que o subtrato composto por $\mathrm{S}_{2}=$ esterco bovino + areia lavada (proporção 2:1) resultou nos melhores resultados, influenciando estatisticamente a nível de $(\mathrm{p}<0,01)$ (figura 1B). Isto se explica possivelmente pela maior proporção de esterco bovino no substrato. Oliveira et al. (2006) observaram efeito significativo do esterco bovino em mudas de mamoneira, onde os melhores 
resultados foram obtidos com a maior dose de esterco bovino e o menor valor sem esterco bovino para a fitomassa seca da raiz.
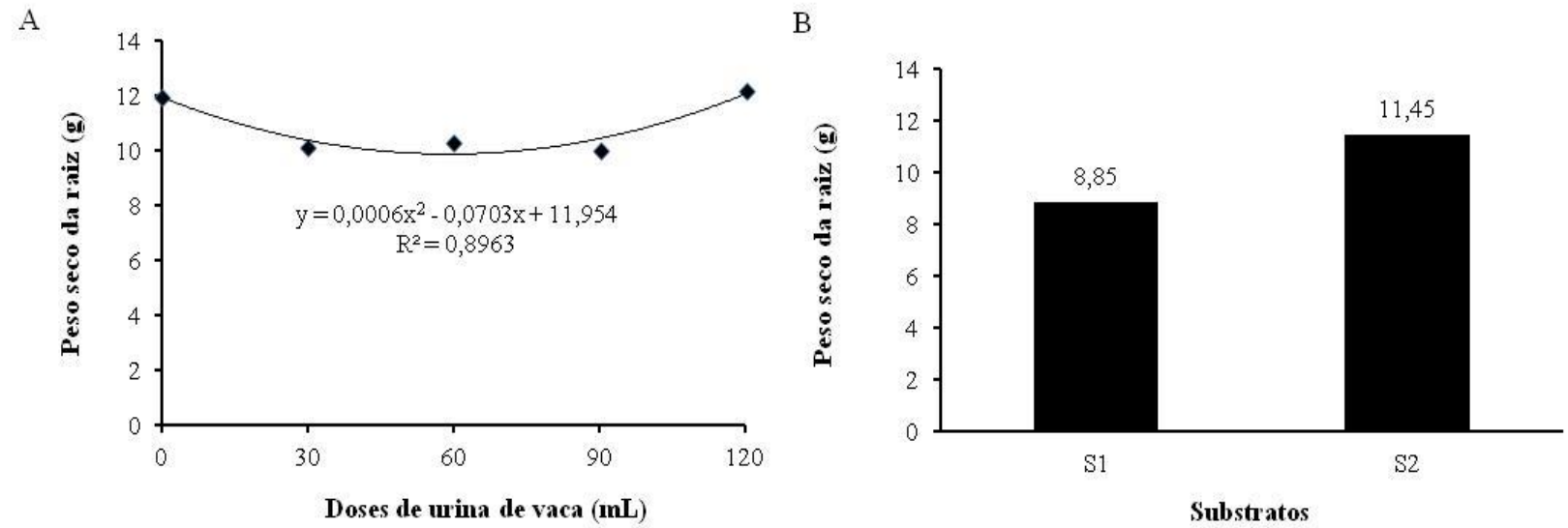

Figura 1: Efeito de doses de urina de vaca (A) e substratos (B) no peso seco da raiz de pimentão

Conforme a figura 2A, o aumento das doses de urina de vaca promoveu um crescimento quadrático para o peso seco do caule, ou seja, a dose máxima de urina de vaca $(120 \mathrm{~mL})$ se sobressaiu melhor em relação as demais doses. Corroborando Véras et al. (2014) em efeito de substratos e fertilização orgânica em plântulas de pinheira, também observaram efeitos significativos com a aplicação de urina de vaca a nível de $\mathrm{P}<0,01$ onde os com os melhores resultados foram obtidos na dose máxima de $100 \mathrm{~mL}$ para o peso seco do caule. Araújo et al., (2014) em estudo envolvendo o crescimento inicial do maracujazeiro sob fertilização orgânica e disponibilidade de água, obtiveram os melhores resultados para a fitomassa seca do caule sem a aplicação de urina de vaca.

O peso seco do caule se comportou semelhante ao peso seco da raiz, onde houve um melhor crescimento com o substrato $S_{2}=$ esterco bovino + areia lavada (proporção 2:1) com uma média de 6,7 g (figura 2B). Conforme Bulluck e Ristaino (2002) uma das características do esterco bovino é que pode apresentar características superiores aos fertilizantes sintéticos, podendo ainda melhorar as propriedades biológicas, físicas e químicas do solo, aumentando a produtividade das plantas. 

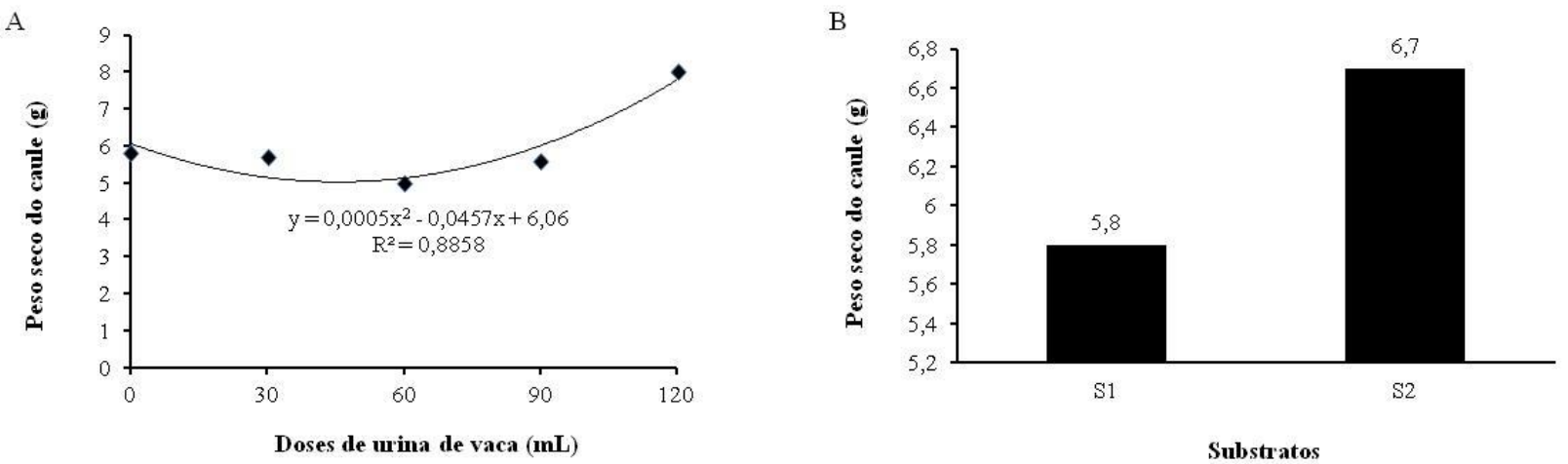

Figura 2: Efeito de doses de urina de vaca (A) e substratos (B) no peso seco do caule de pimentão

As doses de urina de vaca influenciaram significativamente o peso seco da folha, se enquadrando no tipo de regressão quadrática com comportamento convexo, com significância de $(\mathrm{p}<0,01)$, onde o maior valor encontrado foi na dosagem de $120 \mathrm{~mL}$ com 12,1 g, em comparação com a dose de $60 \mathrm{~mL}$ com o menor resultado de 6,2 g (figura 3A). Véras et al., (2014) também obtiveram efeitos positivos com a aplicação de urina de vaca em mudas de pinheira com os maiores valores para o peso seco da folha.

No que se refere aos substratos o $S_{2}=$ esterco bovino + areia lavada (proporção 2:1) obteve o maior resultado com valor de $10,6 \mathrm{~g}$ enquanto que o $\mathrm{S}_{1}=$ pó de madeira + esterco bovino + areia lavada (proporção 1:1:1) foi de $7 \mathrm{~g}$ pelo teste de comparação de médias (Tukey) (figura 3B).
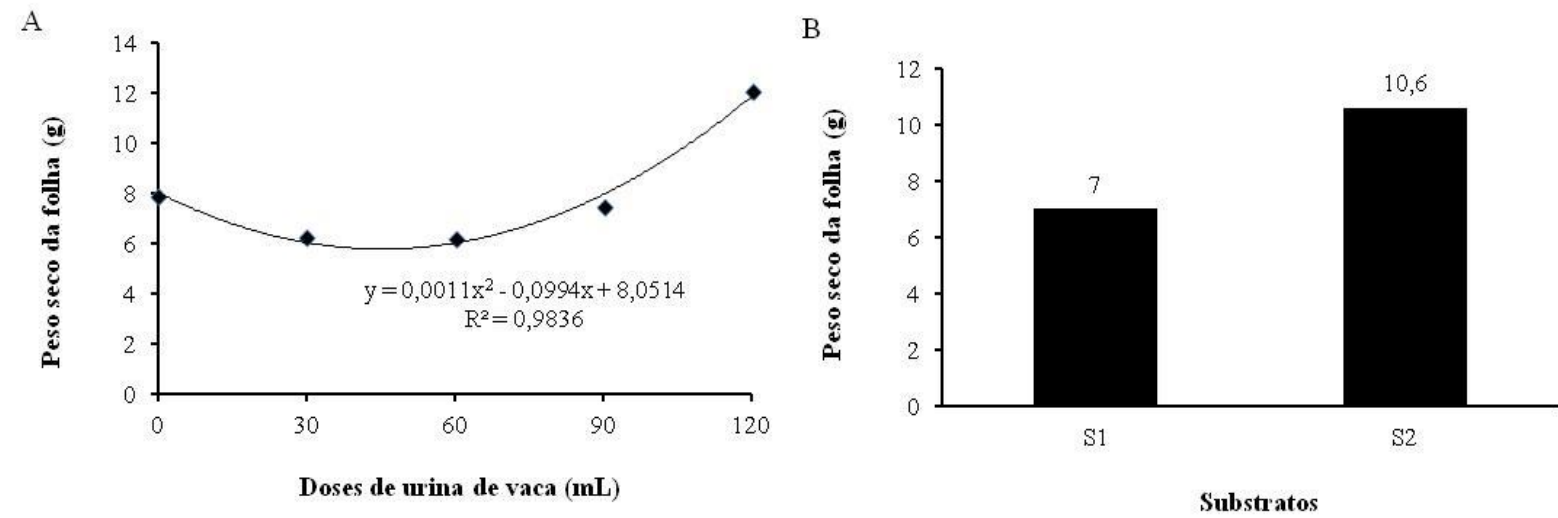

Figura 3: Efeito de doses de urina de vaca (A) e substratos (B) no peso seco da folha de pimentão

Observa-se que as doses de urina de vaca proporcionaram um aumento expressivo conforme o seu aumento para o número de frutos não comerciais se enquadrando no tipo de regressão quadrática com comportamento convexo, onde os maiores valores foram 
constatados com a dose de $120 \mathrm{~mL}$ de urina de vaca com o valor máximo de 2,1 unidades (figura 4A).

No que se refere aos substratos o $S_{2}=$ esterco bovino + areia lavada (proporção 2:1) obteve o maior resultado com valor de 1,7 unidade enquanto que o $\mathrm{S}_{1}=$ pó de madeira + esterco bovino + areia lavada (proporção 1:1:1) foi de 1 unidade pelo teste de comparação de médias (Tukey) (figura 4B).
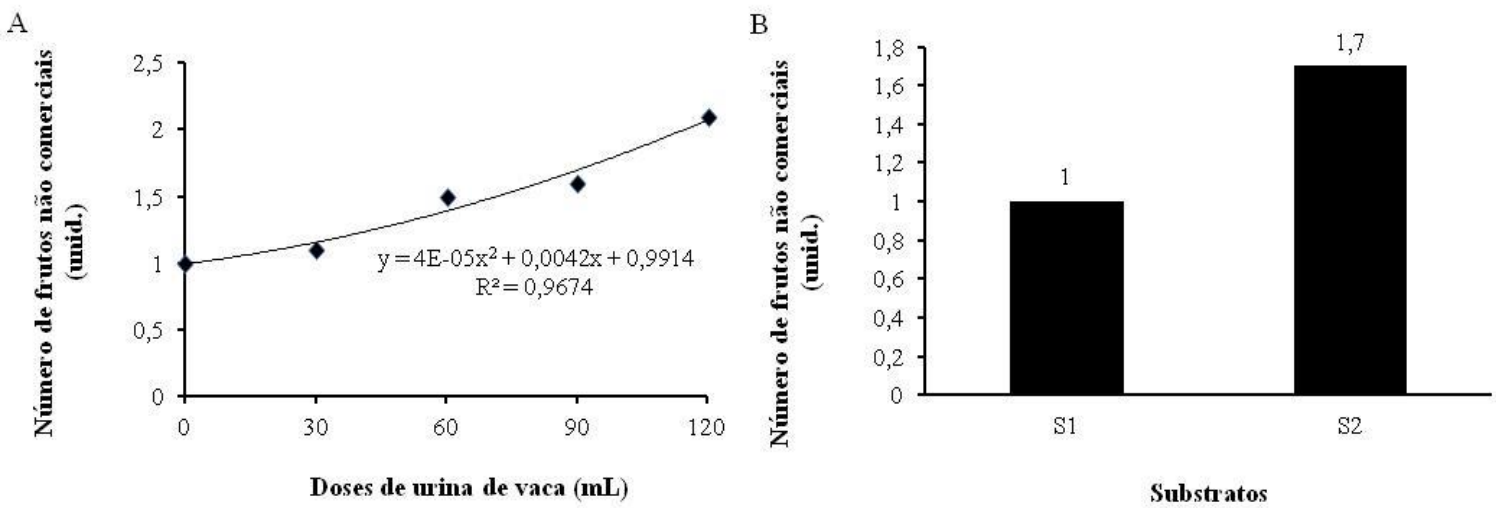

Figura 4: Efeito de doses urina de vaca (A) e substratos (B) no número de frutos não comerciais de pimentão

De acordo com a figura 5A, o aumento das doses de urina de vaca promoveu um crescimento quadrático para o peso de frutos não comerciais, ou seja, a dose máxima de urina de vaca $(120 \mathrm{~mL})$ se sobressaiu melhor em relação as demais doses..

O peso seco de frutos não comerciais se comportou semelhante ao número de frutos não comerciais, onde houve um melhor resultado com o substrato $S_{2}=$ esterco bovino + areia lavada (proporção 2:1) com uma média de $11 \mathrm{~g}$ (figura 5B).
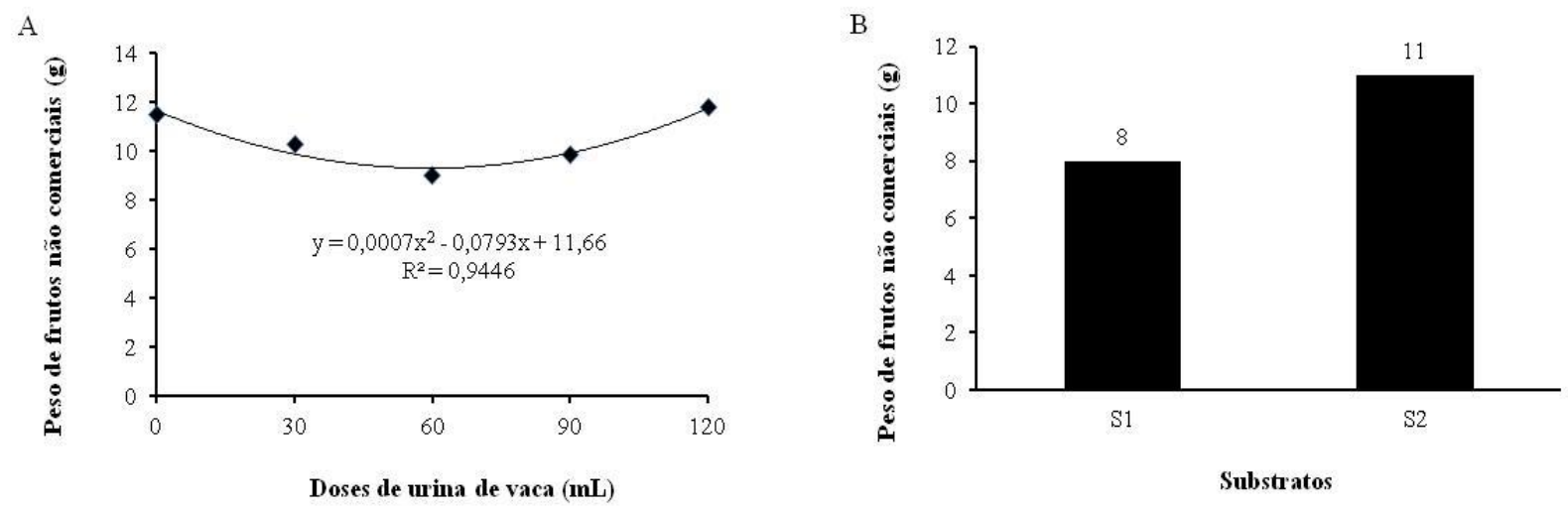

Figura 5: Efeito de doses urina de vaca (A) e substratos (B) no peso de frutos não comerciais de pimentão 
Observa-se na figura 6A que as doses de urina de vaca promoveram um crescimento quadrático para o peso verde total, onde a dose máxima se sobressaiu melhor comparada as demais doses, obtendo o valor de 98,4 g. Araújo et al (2014) estudando níveis de água disponível e doses de urina de vaca no desenvolvimento do meloeiro cantaloupe e observaram que houve influência significativa a nível de $1 \%$ para a fitomassa fresca total com a aplicação da dose $60 \mathrm{~mL}$ de urina de vaca.

Em relação aos substratos, foi observado para o peso verde total que o subtrato composto por $S_{1}=$ pó de madeira + esterco bovino + areia lavada (proporção 1:1:1) resultou nos melhores resultados, influenciando estatisticamente a nível de ( $p<0,01)$ (figura 5B).
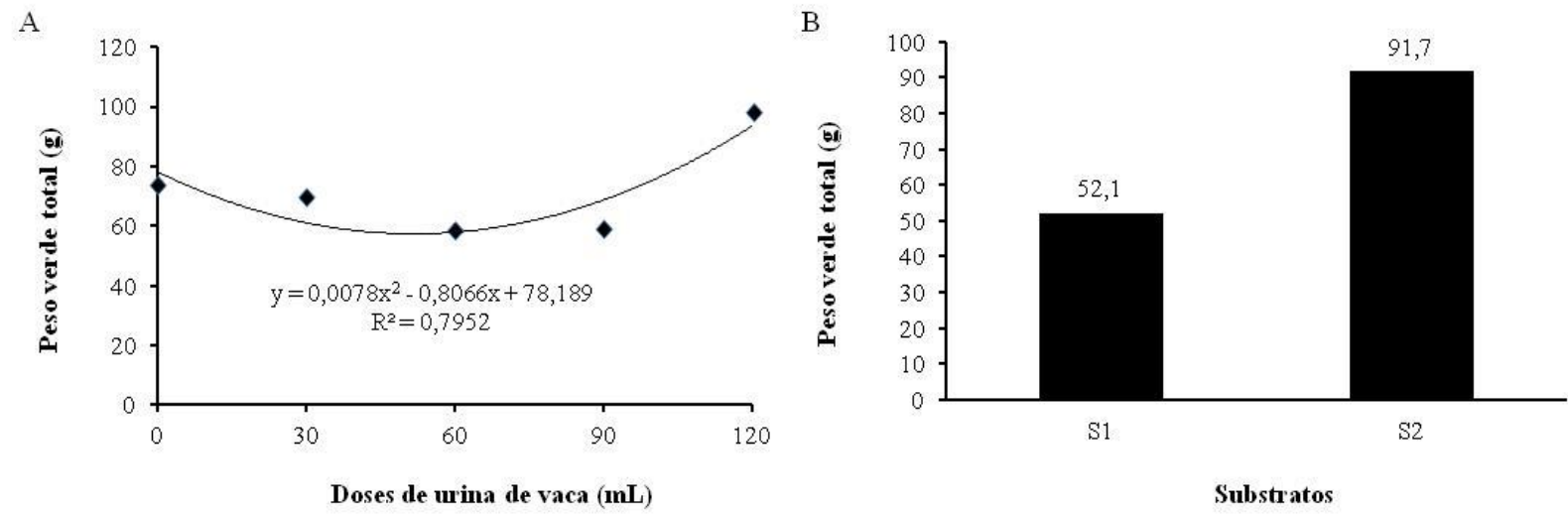

Figura 5: Efeito de doses de urina de vaca (A) e substratos (B) no peso verde total de pimentão

As doses de urina de vaca influenciaram significativamente peso seco total (figura 6A) se enquadrando no tipo de regressão quadrática com comportamento convexo, com significância de $(\mathrm{p}<0,01)$, os maiores valores encontrados foram na dose máxima de $120 \mathrm{~mL}$ de urina de vaca. Resultados semelhantes foram obtidos por Araújo et al (2014) analisando o desenvolvimento inicial do maracujazeiro sob fertilização orgânica e água disponível e constataram que a aplicação de urina de vaca obtiveram os maiores resultados. Diferentemente de Véras et al., (2014) que não observaram efeitos significativos para o peso seco total estudando o efeito de substratos e fertilização orgânica em plântulas de pinheira.

No que se refere aos substratos o $S_{2}=$ esterco bovino + areia lavada (proporção 2:1) obteve o maior resultado com valor de 29,4 g para o peso seco total enquanto que o $\mathrm{S}_{1}=$ pó de madeira + esterco bovino + areia lavada (proporção 1:1:1) foi de 20,6 g unidade pelo teste de comparação de médias (Tukey) (figura 6B). Dantas et al., (2013) estudando o substrato esterco bovino sob diferentes volumes em mudas de pinheira e observaram que a presença de esterco bovino proporcionaram os melhores resultados para a massa seca total. 

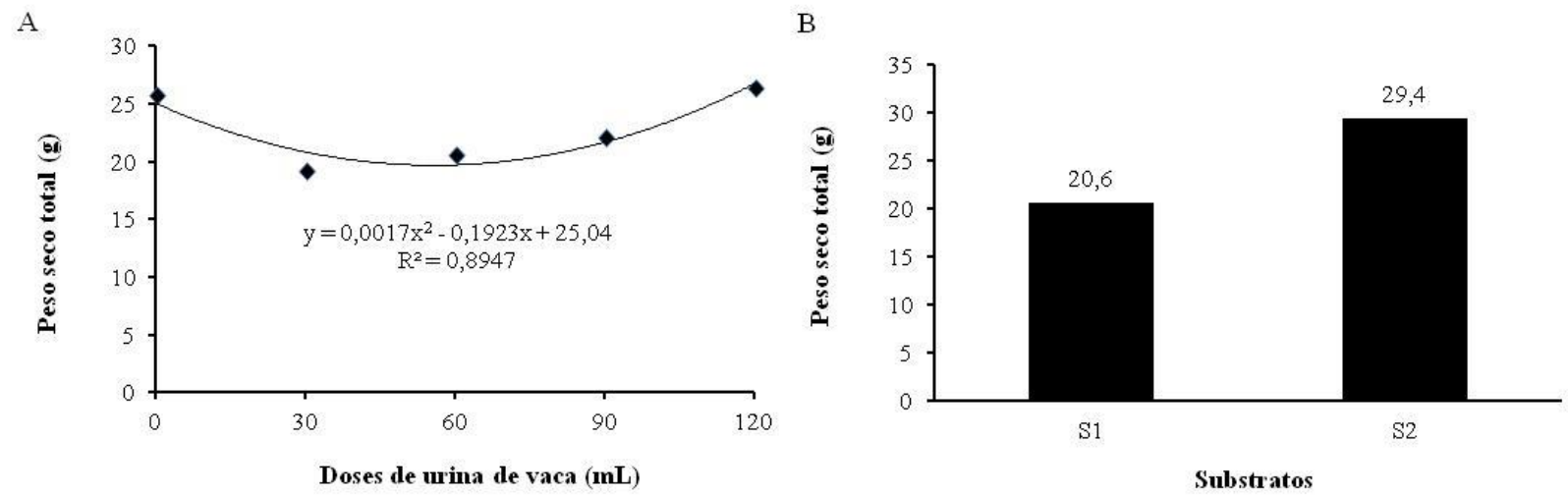

Figura 6: Efeito de doses de urina de vaca (A) e substratos (B) no peso seco total de pimentão

\section{CONCLUSÕES}

A dosagem de $100 \mathrm{~mL}$ de solução a base de urina de vaca proporcionou bons resultados no pimentão.

Substratos com esterco bovino + areia lavada na proporção $2: 1 \mathrm{v} / \mathrm{v}$ são ótimos para a cultura do pimentão.

\section{REFERÊNCIAS BIBLIOGRÁFICAS}

ALBUQUERQUE, F. da S.; SILVA, E. F. de F. e; SOUZA, E. R. de; ROLIM, M. M. Lixiviação de potássio em um cultivo de pimentão sob lâminas de irrigação e doses de potássio. Revista Caatinga, Mossoró, v. 24, n. 3, p. 135-144, 2011.

ALENCAR, T. A. S.; TAVARES, A. T.; CHAVES, P. P. N.; FERREIRA, T. A.; NASCIMENTO, I. R. Efeito de intervalos de aplicação de urina bovina na produção de alface em cultivo protegido. Revista Verde (Mossoró - RN), v. 7, n. 3, p. 53-67, jul-set, 2012.

ARAÚJO, D. L. de; ALVES, L. de S.; VÉRAS, M. L. M.; ANDRADE, R. Desenvolvimento inicial do maracujazeiro sob fertilização orgânica e água disponível. ACSA - Agropecuária Científica no Semi-Árido, v. 10, n. 1, p. 128-133, jan - mar, 2014.

ARAÚJO, D. L. de; ALVES, L. de S.; VÉRAS, M. L. M.; ARAÚJO, D. L. de; ANDRADE, R. Níveis de água disponível e doses de urina de vaca no desenvolvimento do meloeiro cantaloupe. ACSA - Agropecuária Científica no Semi-Árido, v. 10, n. 2, p. 23-28, abr jun, 2014. 
BULLUCK, L. R.; RISTAINO, J. B. Synthetic and organic amendments affect southern blight, soil microbial communities and yield of processing tomatoes. Phytopathology, St. Paul, v.92, p.181-189, 2002.

CHARLO, H. C. O.; OLIVEIRA, S. F.; CASTOLDI, R.; VARGAS, P. F.; BRAZ, L. T.; BARBOSA, J. C. 2011. Growth analysis of sweet pepper cultivated in coconut fiber in a greenhouse. Horticultura Brasileira, 29: 316-323.

DANTAS, G. de F.; SILVA, W. L. da; BARBOSA, M. de A.; MESQUITA, E. F. de; CAVALCANTE, L. F. Mudas de pinheira em substrato com diferentes volumes tratado com esterco bovino e biofertilizante. Revista Agrarian. Dourados, v.6, n.20, p.178-190, 2013.

DIAS, N. S. ; LIRA, R. B.; BRITO, R. F.; SOUSA NETO, O. N.; FERREIRA NETO, M.; OLIVEIRA, A. M. Produção de melão rendilhado em sistema hidropônico com rejeito da dessalinização de água em solução nutritiva. Revista Brasileira de Engenharia Agrícola e Ambiental 14: 755-761. 2010.

GADELHA R. S. S.; CELESTINO, R. C. A.; SHIMOYA, A. Efeito da utilização de urina de vaca na produção da alface. Pesquisa Agropecuária \& Desenvolvimento Sustentável, $1: 179-182,2003$.

GADELHA, R. S. S.; CELESTINO, R. C. A.; SHIMOYA, A. Efeito da urina de vaca na produtividade de abacaxi. Pesquisa Agropecuária \& Desenvolvimento Sustentável vol.1, p. 91-95. 2002.

LEME, S. C. Qualidade pós-colheita de pimentões produzidos em sistema orgânico. 117f. 2012. Tese (Doutorado em Ciência dos Alimentos), Universidade Federal de Lavras, UFLA, Lavras, 2012.

MAROUELLI, W. A.; SILVA, W. L. C. Irrigação na cultura do pimentão. Brasília: Embrapa Hortaliças, 2012. 20p. (Circular Técnica, 101).

OLIVEIRA, N. L. C. de; PUIATTI, M.; SANTOS, R.H. S.; CECON, P.R.; RODRIGUES, P.H. R. Soil and leaf fertilization of lettuce crop with cow urine. Horticultura Brasileira, v.27, p.431-437, 2009.

OLIVEIRA, N. L. C.; PUIATTI, M.; BHERING, A. S.; CECON, P. R.; SILVA, G. do C. C. da. Uso de urina de vaca no cultivo da beterraba de mesa. Revista Brasileira de Agropecuária Sustentável, v.2, n.2., p.7-13, 2012.

OLIVEIRA, N. L. C.; PUIATTI, M.; SANTOS, R. H. S.; CECON, P. R.; RODRIGUES, P. H. R.; BHERING, A. S. Enraizamento e crescimento de mudas de mandioquinha-salsa submetidas à imersão em soluções de urina de vaca. Horticultura Brasileira, v.27, n2. p.1361-1367, 2006.

OLIVEIRA, N. L. C.; PUIATTI, M.; SANTOS, R. H. S.; CECON, P. R.; BHERING, A. S. Efeito da urina de vaca no estado nutricional da alface. Revista Ceres, Viçosa, v.57, n.4, p.506-515, 2010.

PESAGRO. Urina de vaca: alternativa eficiente e barata. Niterói, 2001. 8 p. (PESAGRO. Documento, 68). 
RESENDE, F. V.; VIDAL, M. C. 2011. Sistema Orgânico de Produção de Hortaliças. Disponível em http://itabaiana.seapa.com.br/?p=193. Acesso em: 27 de janeiro de 2015.

SILVA, G. F.; FONTES, P. C. R.; LIMA, L. P. F.; ARAÚJO, T. A.; SILVA, L. F. 2011. Aspectos morfoanatômicos de plantas de pepino (Cucumis sativus) sob omissão de nutrientes. Revista Verde de Agroecologia e Desenvolvimento Sustentável 6: 13-20.

TRANI, P. E.; TERRA, M. M.; TECCIO, M. A.; TEIXEIRA, L. A. T.; HANASIRO, J. Adubação Orgânica de Hortaliças e Frutíferas. Campinas (SP) fevereiro de 2013.

VÉRAS, M. L. M.; ALVES, L. de S.; ARAÚJO, D. L. de; ANDRADE, A. F. de; ANDRADE, R. Crescimento inicial da alface sob fertilização orgânica e volumes de húmus de minhoca. Revista Verde (Pombal - PB), v. 9, n. 2, p. 333-339, Abr -Jun, 2014.

VÉRAS, M. L. M.; ARAÚJO, D. L. de; ALVES, L. de S.; SILVA, T. H. da; ANDRADE, R. Efeito de substratos e fertilização orgânica em plântulas de pinheira. ACSA - Agropecuária Científica no Semi-Árido, v. 10, n. 1, p. 143-149, jan - mar, 2014. 